\title{
Origami contemporâneo: um estudo sobre a arte em dobra e sua mutabilidade prática
}

Contemporary origami: a study of the art in fold and your practice mutability

Samanta Aline Teixeira João Fernando Marar

Dorival Campos Rossi 


\section{Resumo}

Este artigo visa buscar novas formas de manifestação criativa e artística do origami nos dias de hoje. Depois de atravessar inúmeras gerações e países, o que se nota são as funções mais abrangentes do origami além da simples confecção de dobraduras em papel: o dobrar vem desencadeando uma série de novas construções hibridas dentro do projeto e da criação. A modularidade, o coletivo, o construir consciente, $\mathrm{O}$ contemporâneo e a inovação são relações intrínsecas à práxis artística que configuram um panorama adjacente e subordinado à estrutura principal, que rege este projeto de pesquisa. Apostamos na essência do origami como uma funcionalidade tangivel para o pensamento criativo.

Palavras-chave: Origami contemporâneo; Arte, criativo; Dobra.

\section{Abstract}

This article aims to seek new forms of creative and artistic expression origami nowadays. After crossing many generations and countries, we noted that the functions of origami are much broader than simply making folding paper: the folding has promoted a number of new buildings within the hybrid design and creativity. Modularity, the collective, the build conscious, contemporary and innovation are intrinsic relations to artistic praxis that configure an adjacent scenario and subordinate to the main structure that govern this research project. We believe in the essence of origami as a tangible functionality for creative thinking.

Keywords: Origami, contemporary; Art, creative; Fold. 


\section{Introdução}

A arte não consiste mais, aqui, em compor uma "mensagem", mas em maquinar um dispositivo que permita à parte ainda muda da criatividade cósmica fazer ouvir seu próprio canto. Um novo tipo de artista aparece, que não conta mais história. É um arquiteto do espaço dos acontecimentos, um engenheiro de mundos para bilhões de histórias por vir. Ele esculpe o virtual. (LÉVY, 1999, P. 149).

Lévy abre-nos um caminho interessante no que diz respeito ao conceito do virtual, e aos caminhos pelos quais o pensamento artístico está se desenvolvendo na atualidade. Este artigo busca apontar e analisar o origami contemporâneo e a sua virtualidade híbrida. O paradigma da dobra possui uma mutabilidade inata em seu âmago. Isso faz com que a sua natureza criativa esteja presente nos mais variados campos da aplicabilidade projetual, artística e científica. Deleuze já enxergava tal potencial da dobra em meados dos anos 90, conferindo-lhe um conceito muito mais vasto do que mera a intervenção visual e tátil do papel:

Dobras de ventos, de águas, do fogo e da terra e dobras subterrâneas de filões na mina. Os dobramentos sólidos da "geografia natural" remetem, inicialmente, à ação do fogo e, depois, à ação das águas e dos ventos sobre a terra, um sistema de interações complexas. [...] A ciência da matéria tem como modelo o origami, diria o filósofo japonês, ou a arte de dobrar o papel. (DELEUZE, 1991, p. 18).

O origami (ou dobradura) dos dias de hoje tem contribuindo amplamente para novas reflexões e artefatos devido a sua atípica e singular estética, como demonstrados nos quatro exemplos abaixo.

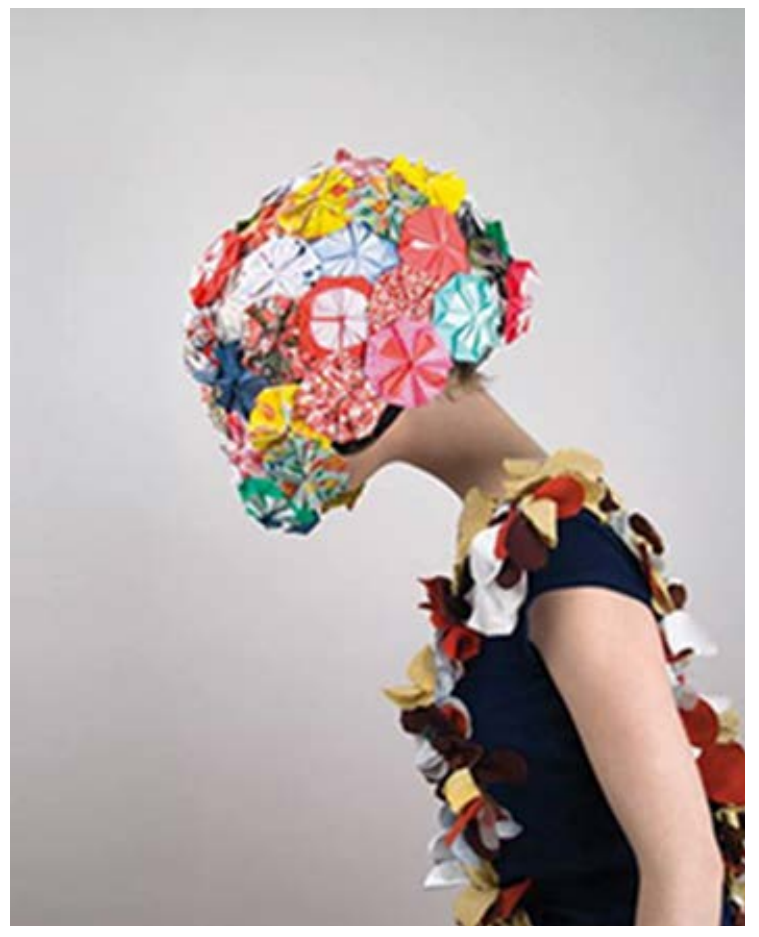

Figura 1. O trabalho artístico "Faux Plis", pela designer têxtil Aude Mercier, e pela fotógrafa Véronique Pêcheux, em 2009. Fonte: MERCIER, A. PÊCHEUX, V. Faux Plis. [S.I.: s.n.], 2009. Disponível em: <http://www.veroniquepecheux.com/>. Acesso em: 20 jul. 2014. 
A série fotográfica "Faux Plis", Figura 1, foi desenvolvida pela designer têxtil Aude Mercier, e pela fotógrafa Véronique Pêcheux. Utilizando a linguagem das dobraduras, dos tecidos e do hand made ${ }^{1}$, as duas artistas uniram-se para criar essa série que parece envolver-se um pouco do surrealismo, especialmente com relação às obras do artista belga René Magritte. A utilização da fotografia envolvendo a figura humana e os artefatos em origami e tecido traz uma reflexão sobre a questão da mistura, ou mestiçagem, descrita por Serres:

Ninguém pode pensar a mudança, a não ser sobre misturas: quando se tenta pensar sobre os simples, só se chega a milagres, saltos, mutações, ressurreições, até a transubstanciação. Eis a mudança em títulos, em ligas, em tecidos e mapas, eis a mudança por desenhos e reações, chamalote sobre chamalote, mestiçagem. (SERRES, 2001, p. 23).

Plasticamente, as artistas trabalham em cima da conversação subjetiva entre o que pode ser mutável, especialmente sobre os diferentes materiais e aplicações dos mesmos. A Figura 2 também diz respeito à mistura, mais especificamente da mistura do origami com o meio urbano.

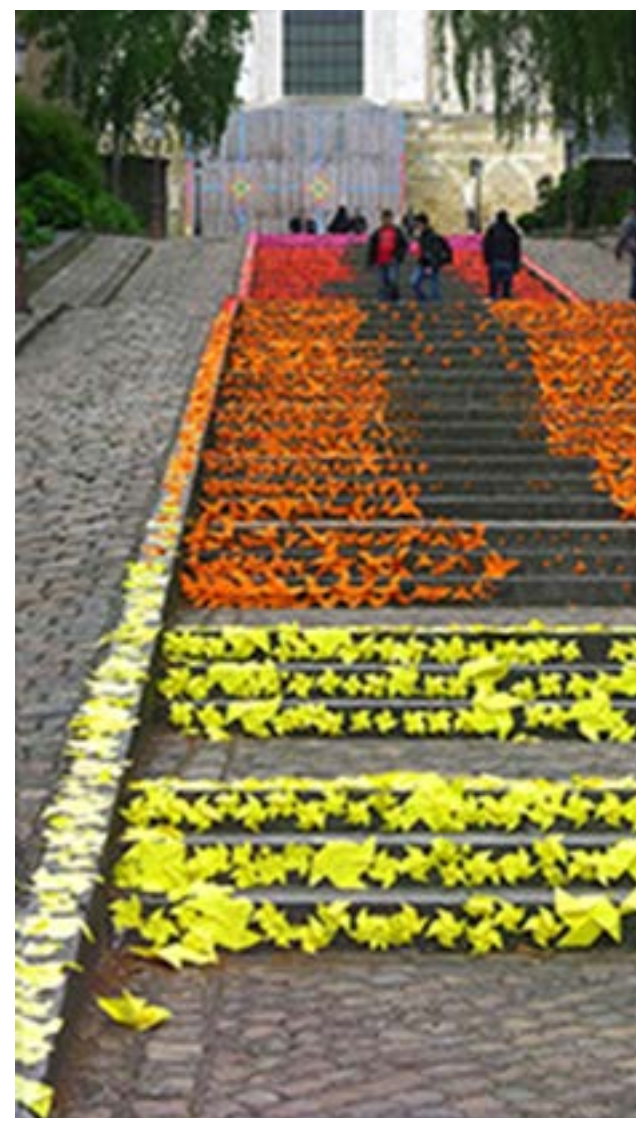

Figura 2. Intervenção urbana feita com 30.000 origamis pela artista francesa Mademoiselle Maurice no Festival de Arte Urbana ARTAQ 2013, em Angers, França. Fonte: JOBSON, C. New Origami Street Art in Angers, France by Mademoiselle Maurice. [S.I.]: Colossal, 2013. Disponível em: <http://www.thisiscolossal.com/2013/06/new-origami-street-art-in-angers-france-by-mademoiselle-maurice/>. Acesso em: 20 jul. 2014.

1 Termo utilizado para designar tudo o que é feito à mão. 
A intervenção dos origamis de Mademoiselle Maurice ocupam os meios de passagens comuns da cidade. A mestiçagem descrita por Serres ocorre na mistura de cores vivas das dobraduras com o cinza das praças, paredes e chãos; há uma aglutinação entre o maquinário "duro" do meio urbano e o fazer manual "mole" conferido aos origamis. Numa mescla entre questionamento e experiência coletiva das cidades e seus espaços, Mademoiselle Maurice pontua o que Argan também descreve com relação às intervenções artísticas:

No campo da arte, em que especialmente se refletem as ideias relativas ao criar, afirma-se de maneira cada vez mais explícita (com Duchamp, por exemplo) que o artista não tem como fim a criação de obras de arte e que sua criatividade pode ser consumada experimentando esteticamente, ou seja, de forma livre e criativa, a realidade do ambiente. (ARGAN, 2005, p. 254-255).

A Figura 3 apresenta um projeto mais versado entre o usuário e o objeto articulado pela dobra.

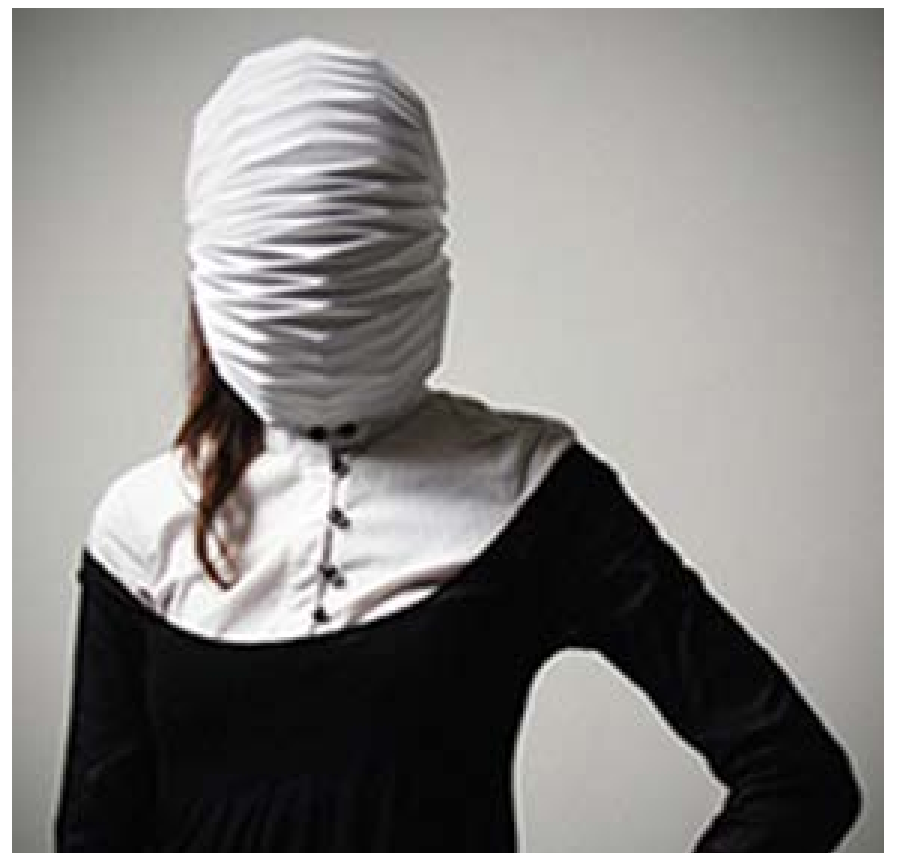

Figura 3. O conjunto de acessórios portáteis "Veasyble", projetados pelo grupo Gaia (Adele Bacci, Arianna Petrakis, Ilaria Pacini e Gloria Pizzilli), feitos com papel, polietileno e tecido. Fonte: HERNANDEZ, R. Veasyble by GAIA. [S.I.]: Yatzer, 2010. Disponível em: <http://www.yatzer. com/Veasyble-by-GAIA>. Acesso em: 20 jul. 2014.

O projeto "Veasyble" incorpora a mensagem pela mensagem, ou ainda, a linguagem pela linguagem. Projetos como este permeiam mais pela estética da dobra e suas possibilidades de ação do que pelo seu utilitarismo único e exclusivamente. Esse comportamento, de acordo com Serres, reflete a nossa nova realidade contemporânea:

Ainda nos prendíamos com amarras, cabos e ancoragens, às próprias coisas pela observação, pela ideia da clareza. [...] As amarras se soltam. A mensagem torna-se o próprio objeto. [...] a idade da mensagem mata a era teórica. (SERRES, 2001, p. 45). 
"Veasyble" constitui-se como uma série de objetos desenhados para o uso de uma ou duas pessoas e incorpora especialmente o conceito da particularidade, do íntimo e da isolação social. Ao mesmo tempo, a série feita pelo grupo Gaia também possui a mutabilidade da dobra. Os objetos se expandem e se contraem num processo que não tem fim nem começo; ambos os estados formais das dobraduras de "Veasyble" estão intrínsecos uns nos outros.

Como último exemplo dessa introdução, cita-se a Figura 4, o projeto de produto "Oyster". Diferente do projeto "Veasyble", "Oyster" possui um claro objetivo de utilização, embora usufrua da linguagem do origami para a sua concepção.

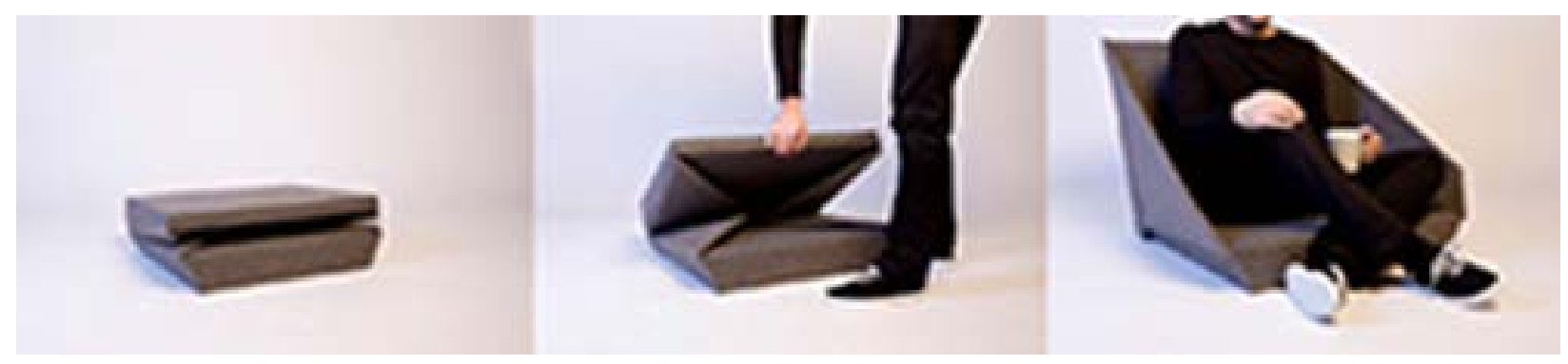

Figura 4. O mobiliário "Oyster", mistura de almofada e cadeira que economiza espaço, feito pelo estúdio de design e arquitetura Kawamura-Ganjavian. Fonte: GANJAVIAN, A. KAWAMURA, K. P. Oyster. [S.I.: s.n.], 2009. Disponivel em: <http://www.studio-kg.com/oyster/>. Acesso em: 20 jul. 2014

As dobras de "Oyster" são simples, todavia contundentes, específicas e projetadas especialmente para serem mutáveis. "Oyster" possui uma gestão de economia de espaço e transporte interessantes tanto ao usuário quanto às fábricas de móveis.

Os projetos anteriormente citados demonstram claramente que as dobraduras têm adquirido grande potencial de ação em metaprojetos das mais diversas naturezas e lançados todos os dias. Cabe identificar as novas características pelas quais o mundo está passando com a revolução digital da comunicação, bem como entendê-las. $A$ presença constante da internet e dos dispositivos móveis nos torna conectados globalmente em full time.

As pessoas deixaram de ser expectadoras passivas do conhecimento e entretenimento para se tornar seres ativos e decisivos na sua própria construção. Assim constata Serres:

A filosofia clássica confiava até recentemente na iluminação, a filosofia contemporânea descobre a rapidez do raio. [...] A rede de comunicação torna inútil a presença, não tem centro; torna obsoleta a vigilância. Os circuitos audiovisuais ou informatizados fazem rir os admiradores da última guerra presos aos campos de batalha romanos. [...] O mundo da informação toma o lugar do mundo observado. (SERRES, 2001, p. 44-45).

Vídeos, blogs, redes sociais e toda a digitalização dos meios de comunicação tornaram possível o conhecimento compartilhado de maneira horizontal, de pessoa para pessoa; diferente do que acontecia anteriormente, com o conhecimento transmitido apenas de uma autoridade hierárquica para com seus subordinados. Esses aconteci- 
mentos fizeram com que os limites entre arte, design e ciência se tornassem cada vez mais próximos: tal como um rizoma ${ }^{2}$, fica difícil saber onde a ciência começa e onde a arte ou o design termina. Tal evidência é defendida por Flusser (2007, p. 32): "Fazia sentido, antigamente, diferenciar a ciência da arte, o que hoje parece um despropósito.". O pensamento de que o criativo projetual permeia sob a área das ciências é apontado também por Bonsiepe (2011, p. 19): "Não se pode mais restringir o conceito de projeto às disciplinas projetuais [...], pois nas disciplinas científicas também há projeto.". A transdisciplinaridade é uma evidência contemporânea factual uma vez que "[...] as novas tecnologias extravasam o purismo conceitual." (BONSIEPE, 2011, p. 144).

Pode-se notar que o origami, na condição de ferramenta criativa e objeto de estudo, possui tal caráter mutante, subjetivo, mas verídico. Veremos a seguir mais algumas evidências mais aprofundadas do comportamento da dobra e do origami, bem como suas análises.

\section{Desenvolvimento}

O origami tem sua origem desde os anos 1600 (HULL; LANG, 2005). Sua natureza oriunda desde os seus primeiros indícios na China até a sua adaptação e consagração no Japão tem desencadeado uma série de mudanças paradigmáticas cruciais ao ramo criativo e artístico. A prática e busca do conhecimento através do origami é realidade cada vez mais constante em diversos países. Isso ocorre devido à natureza das dobraduras, que abarcam não apenas a mutabilidade da dobra, mas também toda a filosofia e cultura oriental. Assim afirma Flusser (2007, p. 209):

Enquanto no Ocidente o design revela um homem que interfere no mundo, no Oriente ele é muito mais o modo como os homens emergem do mundo para experimentá-lo. Se considerarmos a palavra estético em seu significado originário (isto é, no sentido de "experimentável", de "vivenciável"), podemos afirmar que o design no Oriente é puramente estético.
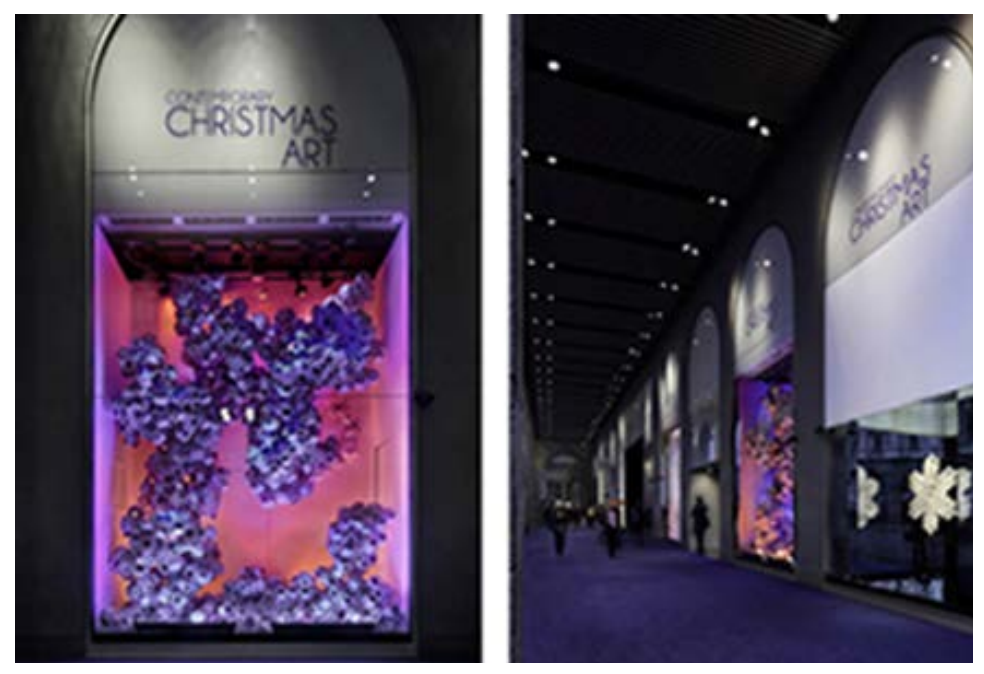

Figura 5. A vitrine "Origami Coral Reef", da loja La Rinascente, construído com 1500 papelões reciclados e recicláveis, trabalho feito pelo Laboratório de Arquitetura Visionária - LAVA. Fonte: BOSSE, C. RIECK, A. WALLISSER, T. Milan Rinascente window. Milão, [s.n.], 2010. Disponível em: <http://www.l-a-v-a.net/projects/milan-rinascente-window/>. Acesso em: 20 jul. 2014. 


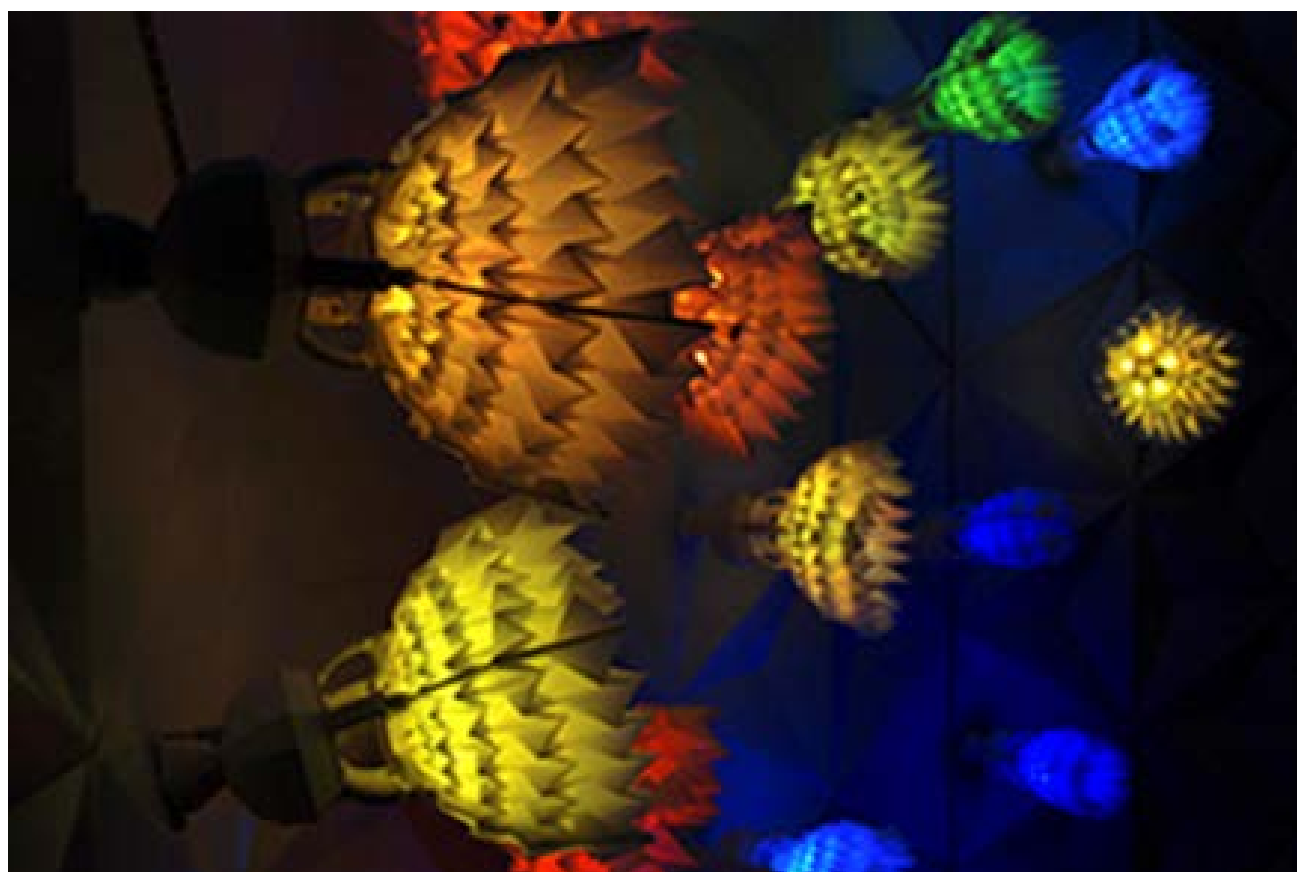

Figura 6. Instalação interativa "Oribotics", pelo artista Matthew Gardiner. Os origamis cinéticos abrem e fecham por eletricidade remota - os materiais incluem impressão 3D, modelagem, corte a laser, e técnica de fabricação artesanal. Fonte: GARDINER, M. Oribotics. [S.I.: s.n.], 2004. Disponivel em: <http://matthewgardiner.net/art/Oribotics_origin>. Acesso em: 09 nov. 2014.

As intervenções exemplificadas acima evidenciam que o dobrar vem sendo encarado pelos artistas/designers, em essência, como uma filosofia (e consequentemente como uma ferramenta) complexa e renovadora aos olhos do mundo contemporâneo. Ao que se nota, o origami encontra-se no seu melhor momento atualmente (HULL; LANG, 2005): "Durante os últimos 35 anos ou mais a arte do origami tem renascido". Mas como se deu este salto tão grande entre o dobrar de papel para outras vias de criação, materiais e reflexão do origami?

Onde e como introduzir uma folha entre duas páginas, por onde passar, por qual espaço? (...) É preciso imaginar dobraduras, invaginações, situações extraordinariamente complexas que generalizam a prática e a noção de nó em todas as dimensões imagináveis. (SERRES, 2001, p. 74-75).

De acordo com Serres (2001), dobrar e atar um nó constituem-se como atividades virtuais muito próximas entre si. Significa essencialmente plasmar uma ideia (virtual) para então estar apto a concretizá-la em um produto, objetivo ou ato (real). Este ato elucidado e alicerçado do conceito pelo próprio conceito pode ser essencial em diversos tipos de projetos, sejam eles grandes ou triviais. Em verdade, milhares de ramos/ disciplinas/áreas que antes eram cuidadosamente separadas pelas escolas estão sendo aglutinadas e incorporadas entre si. Isso por conta da autoconsciência do pensamento complexo que, combinando o caos à ordem, faz com que tal paradigma faça mais jus à nossa realidade, como confirma Edgar Morin (2006, p. 13-61):

A complexidade é efetivamente o tecido de acontecimentos, ações, interações, retroações, determinações, acasos, que constituem nosso mundo fenomênico. [...] A dicotomia não era mais possível. Foram necessárias estas últimas décadas para que nos déssemos conta de que a desordem e a ordem, sendo inimigas uma da outra, cooperavam de certa maneira para organizar o universo. 
Pode-se dizer que o início dessas junções de áreas do conhecimento começou com o design, de acordo com Flusser (2007, p. 183):

A cultura moderna, burguesa, fez uma separação brusca entre o mundo das artes e o mundo da técnica e das máquinas. (...) A palavra Design entrou nessa brecha como uma espécie de ponte entre esses dois mundos.

Para Flusser (2007, p. 28), a informação não está apenas na língua e nas escritas, mas também nas formas que o designer ou artista cria. Portanto, conscientizar-se dos diferentes tipos de ferramentas e de como as formas são "informadas" precisa estar consciente desde o início. É a partir de então que a filosofia/cultura oriental entra como uma informação relevante, sendo uma forma de raciocínio vasta e ao mesmo tempo simples, contundente:

Podemos observar como surgem formas entre as mãos dos orientais, por exemplo, ideogramas escritos com pincel, flores de papel (...). Em todos esses casos não se trata de uma ideia imposta sobre algo amorfo; trata-se de fazer surgir de si mesmo e do mundo circundante uma forma que abarque ambos (FLUSSER, 2007, p. 208).

Azevedo (1994, p. 75) também constata na cultura japonesa a relevância necessária aos nossos olhos ocidentais: "Buscar inspiração na natureza é uma tarefa difícil nos tempos de hoje, mas os japoneses parecem lidar com a eletrônica com a mesma facilidade com que seus antepassados ouviam o vento". O origami entra no grande leque de signos orientais como parte visceral de sua cultura e filosofia de vida. Todavia, nota-se que o origami contemporâneo já não faz mais parte do Japão ou China exclusivamente: ele partiu do mundo asiático para se tornar propriedade intelectual e criativa em todo o globo.

\section{A dobra brasileira: o tátil de Lygia Clark}

No período de 2 de setembro a 11 de novembro de 2012, aconteceu a exposição "Lygia Clark, uma retrospectiva" no prédio Itaú Cultural, em São Paulo. Em nossa visita à exposição, identificamos no trabalho de Clark diversos aspectos que se conectam com o origami de forma direta ou indireta. Diz o texto "Dobras", exposto em um dos ambientes da mencionada exposição:

Essa potência que torna o expectador um sujeito ativo, do mesmo modo que articula uma expansão do espaço arquitetônico, promovendo distintas colaborações, pode ser identificada como dobra: as curvaturas da dobra entrelaçam-se sem ser possível distinguir o que está fora ou dentro, numa espécie de embaralhamento de campos e conceitos. 


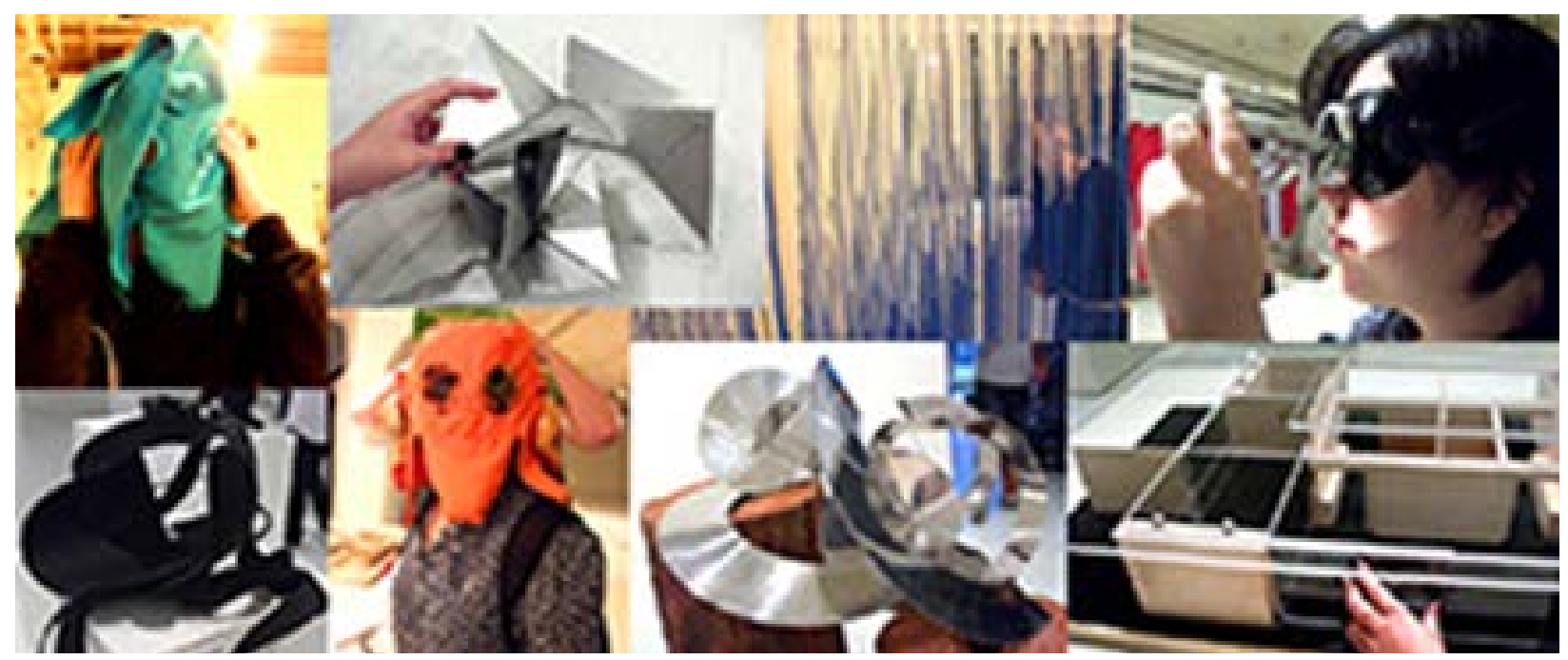

Figura 7: Reunião de fotos da exposição "Lygia Clark: uma retrospectiva”. Fonte: elaborado pelo Autor (2012).

Lygia Clark nasceu no ano de 1920, em Belo Horizonte. Em 1947, iniciou seus estudos artísticos, foi fundadora do Grupo Frente (1954) e do Manifesto Neoconcreto (1959). O maior foco de seu trabalho era a busca de quebra do espaço artístico "emoldurado/contemplado" através de uma interligação da obra com o usuário à base da exploração e contato direto, especialmente no caráter tátil humano. A troca de prioridade sensória da visão (a que predominou durante todo o período do design moderno e pós-moderno) para o tato desencadeia uma mudança perceptiva relevante, como evidencia Serres (2001, p. 80): “O puro tato abre para a informação, correlato doce do que antigamente era chamado de o intelecto". Por essas evidências, Clark acreditava que os objetos só possuíam algum devir se fossem tocados, sentidos, como explica o texto da exposição:

A ideia de dobra dialoga com as mais importantes questões levantadas por Clark: a 'função' do artista num momento em que o expectador é incentivado a ser parte de um processo chamado por ela de 'proposição', isto é, o objeto de arte torna-se o mediador de uma experiência oferecida pelo propositor (e não mais artista) e que só adquire sentido ou imanência quando o participante interage com esse objeto e lhe transmite potência ou 'camadas de subjetivação'.

Ou seja, a artista buscava o conceito e aplicação do que chamamos hoje de objeto sensível. Os trabalhos mais famosos de Clark são os "Bichos", de 1960 - esculturas de alumínio com diversas dobradiças, podendo o usuário manipulá-las a seu bel prazer, gerando diferentes formas e experiências. Muitos dos esboços, construções e experimentos de Lygia se assemelham intimamente aos diagramas de origami: 


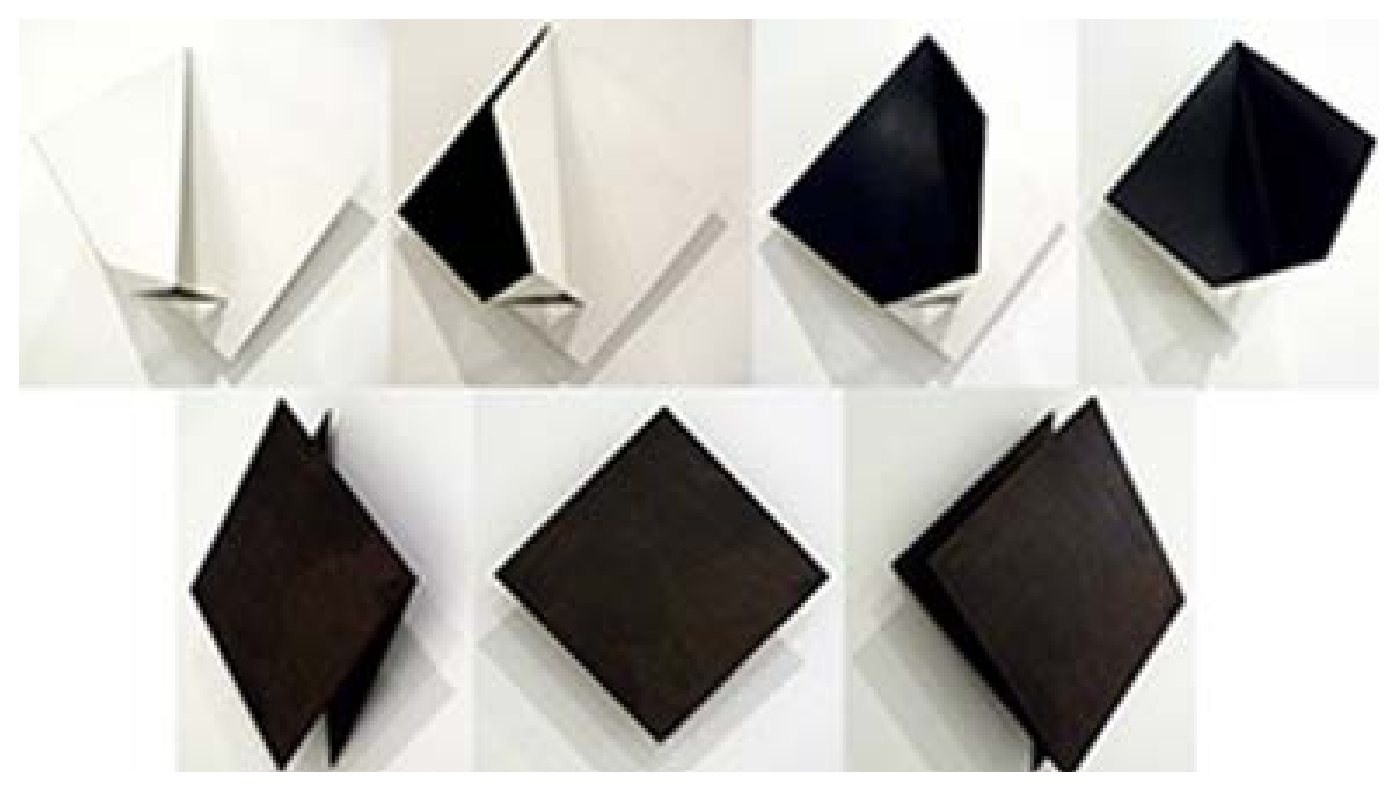

Figura 8: Duas versões diferentes de "Casulo" ou “Cocoon”, 1959/1984. Fonte: elaborado pelo Autor (2012).

As obras "Casulo", de Clark, foram uma das tentativas da artista de sair da padronização dos quadros emoldurados, buscando um novo suporte para o objeto e incorporando o plano da tridimensionalidade. Tais trabalhos são extremamente semelhantes à base do origami tradicional tsuru (Cf. Figura 10) e eles se compõem com o raciocínio compacto da dobra.

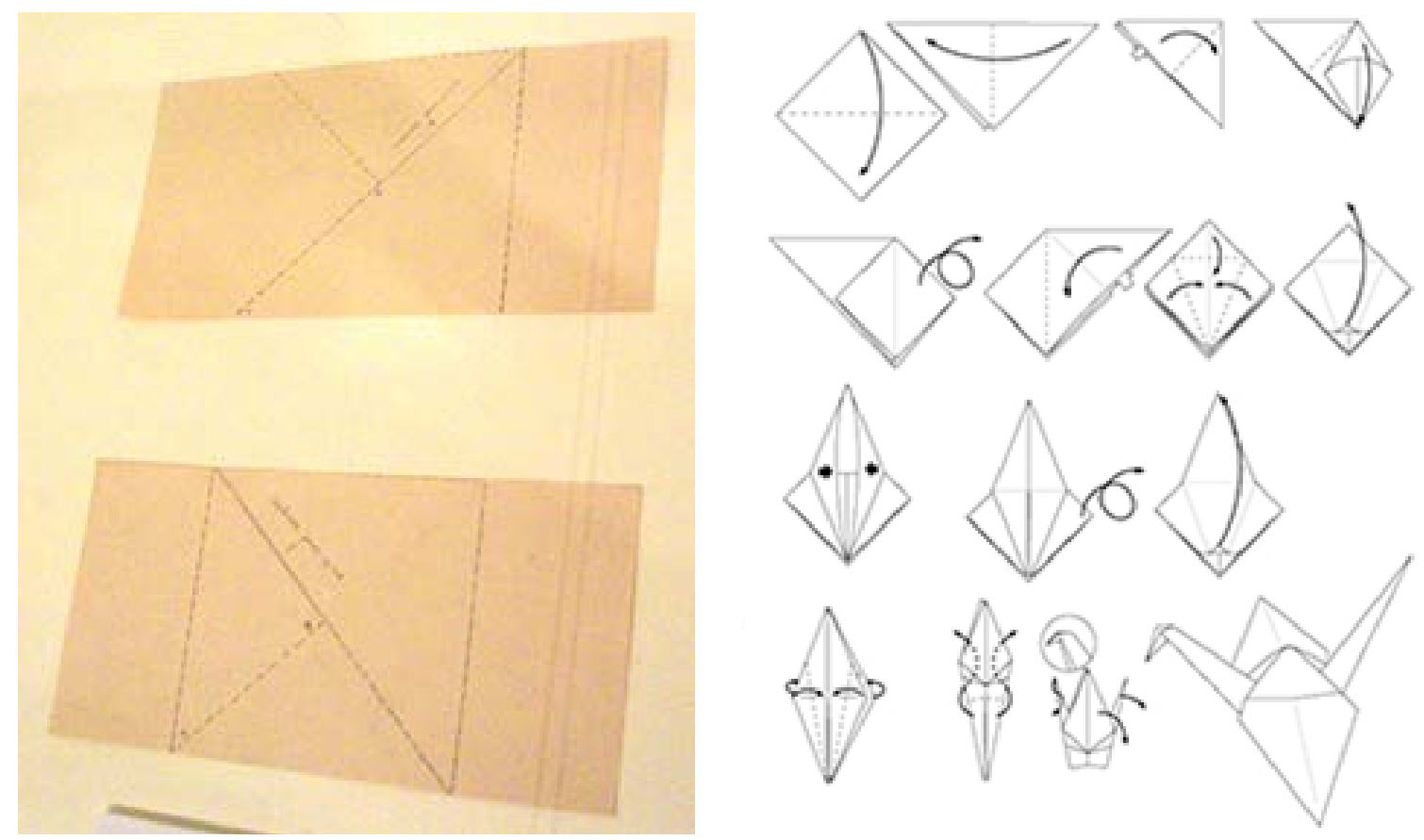

Figuras 9 e 10: À esquerda, rascunhos de estudos construtivos de Clark; à direita, um diagrama do origami tsuru. Fonte: elaborado pelo Autor (2012).

A construção de um origami e os esboços de Lygia se conectam em diversas perspectivas: são utilizadas linhas de corte, tracejados onde ocorrem as dobras, setas indicando caminhos, a forte presença do uso de ângulos agudos ou obtusos e a geometria plana que se transforma em geometria tridimensional. 
Se por um lado Clark sempre procurou o contato direto das pessoas com os objetos, o origami nasceu exatamente dessa forma. As dobraduras só existem se alguém as experimentar/conceber. O surgir da forma através de seus próprios atos de dobras táteis, numa mistura de interações individuais e coletivas - são essas as principais características em comunhão entre Lygia Clark e o origami.

\section{O Laboratório LAVA e outros exemplos da arte do origami contemporâneo}

Como exemplo aplicado às artes contemporâneas, ao design e à arquitetura em conexão com as dobraduras, constatamos determinados edifícios que desafiam tanto a gravidade quanto os limites de formato. Tais edificações pertencem ao LAVA - Laboratório de Arquitetura Visionária. Fundado em 2007, por Chris Bosse e Tobias Wallisser, a empresa possui sedes na Alemanha, Austrália e Unidos Árabes e vincula pesquisas de diversas áreas às equipes profissionais, em busca de inovação, tecnologia e diferencial.

Nesse ínterim, notamos um padrão: assim como o origami desafia os formatos do papel, o LAVA desafia as construções urbanas, fazendo com que os limites entre a engenharia dos materiais e os ideais do design/arte estejam cada vez mais estreitos.

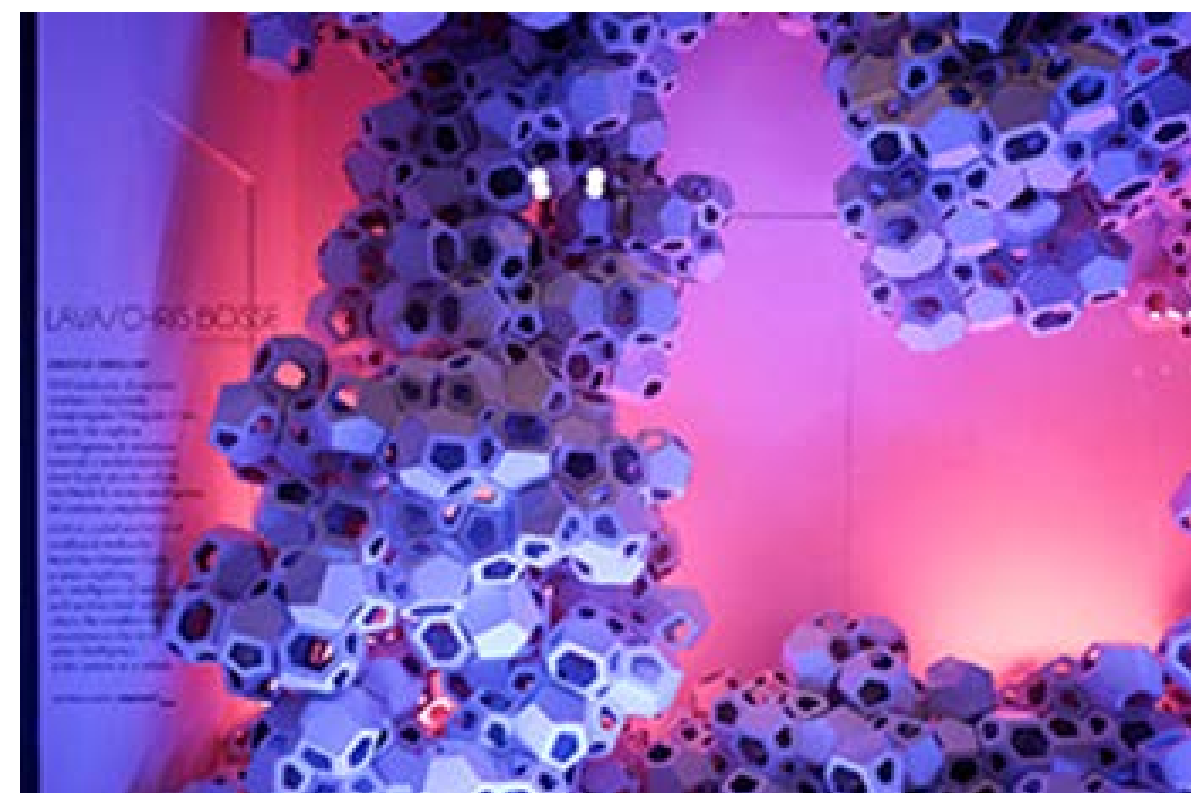

Figura 11: Vitrine de uma loja italiana, origamis elaborados pelo LAVA. Fonte: BOSSE, C. RIECK, A. WALLISSER, T. Milan Rinascente window. Milão, [s.n.], 2010. Disponível em: <http://www.l-a-v-a.net/projects/milan-rinascente-window/>. Acesso em: 20 jul. 2014.

A imagem acima é um dos trabalhos do LAVA: a vitrine "La Rinascente" foi feita com 1500 origamis em papéis reciclados que incorporam a dinâmica dos recifes de corais. Segundo C. Bosse (2014), um dos criadores da vitrine, os corais possuem um comportamento organizacional inteligente, regido plenamente pela sustentabilidade. O desenvolvimento sustentável não diz respeito somente à gestão em prol da preservação da natureza. O pensar sustentável confere feedback tanto para o meio quanto para o usuário, ao mesmo tempo em que reforça a importância dos estudos criativos - assim descreve Thierry Thouvenout (apud KAZAZIAN, 2005, p. 8): 
Se o desejo é o motor do desenvolvimento sustentável, a criatividade é seu combustível: é a criatividade que dará o impulso ao empreendedor para imaginar um produto ou serviço que ofereça mais (satisfação às necessidades) com menos (recursos e trabalho). [...] É a criatividade que vai permitir ao pesquisador encontrar soluções elegantes para problemas cada vez mais complexos.

A sustentabilidade, em convergência com raciocínios da natureza e a linguagem dos crafts $^{3}$ - como o origami - é uma das muitas conexões que o LAVA se dispõe a elaborar em seus projetos. Outro projeto de uso claro à linguagem do origami é o abrigo para emergências Digital Origami Shelter, baseado na molécula de água e nos hotéis-cápsulas japoneses.

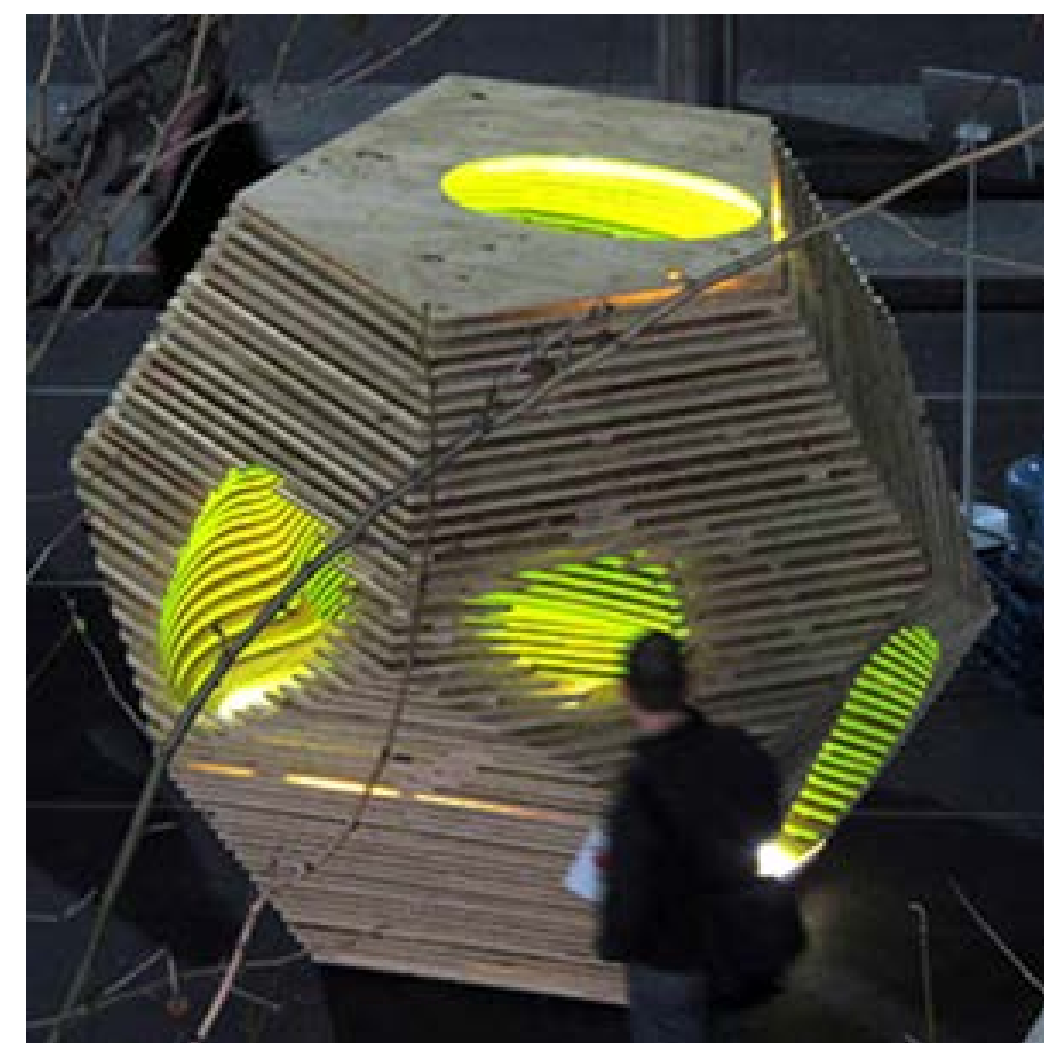

Figura 12: Digital Origami Shelter, por LAVA. Fonte: BOSSE, C. RIECK, A. WALLISSER, T. Digital origami emergency shelter. Austrália, [s.n.], 2011. Disponivel em: <http://www.l-a-v-a.net/projects/digital-origami-emergency-shelter/>. Acesso em: 09 nov. 2014.

O abrigo tem a versatilidade de ser pequeno, fácil de ser construído e carregado por helicópteros em situações de emergência. Possui um espaço para dormir dois adultos e uma criança, além de outro espaço menor parar comer e ler. A empresa acredita que cada novo projeto de arquitetura carrega uma ampliação da tecnologia contemporânea e, por isso, carrega também uma grande responsabilidade com o público e o meio-ambiente. 


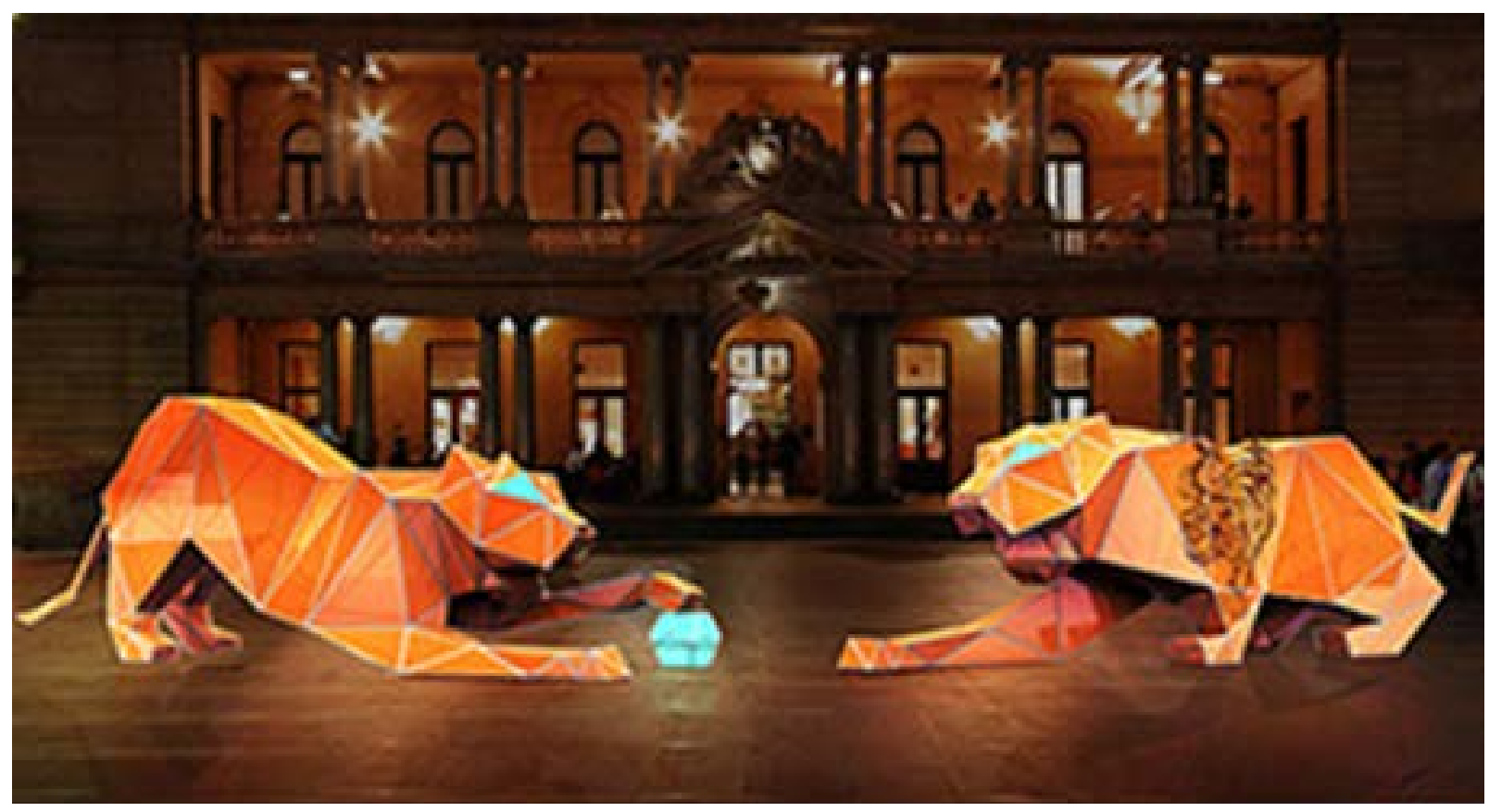

Figura 13: Dois tigres em forma de origami para celebrar o Ano Novo Chinês, por LAVA. Fonte: BOSSE, C. RIECK, A. WALLISSER, T. Digital origami tigers. Austrália, [s.n.], 2010. Disponível em: <http://www.l-a-v-a.net/projects/digital-origami-tigers/>. Acesso em: 09 nov. 2014.

Utilizando a linguagem do Festival das Lanternas Chinesa mais a combinação do zhezhi (dobradura em chinês), o LAVA criou em 2010 as esculturas "Digital Origami Tigers". São as figuras de dois tigres agachados para celebrar o feriado mais importante da China, o Ano Novo Lunar Chinês. Instalados no pátio de Customs House, em Sydney, a empresa projetou os gigantes tigres com 2,5 metros de altura por 7 metros de comprimento e ambos possuem 200 quilos. As esculturas foram feitas apenas com materiais recicláveis, alumínio e barrisol ${ }^{4}$, e a adição da iluminação de baixa energia das lâmpadas LED. As esculturas também simbolizam a preocupação com a extinção de diversos animais, entre eles os tigres. Esse projeto reflete a possível interação entre as tradições culturais com as experimentações tecnológicas contemporâneas.

Além do aspecto de conexão interativa que a linguagem do origami resguarda, apontamos uma nova mudança de paradigma também baseada no craft, que literalmente significa "ofício", "habilidade", e designa o fazer manual, artesanal. O craft é uma técnica originária dos tempos mais longínquos da Pré-História, mas que vem sendo resgatado e utilizado em muitos processos artísticos contemporâneos.

Podemos, no entanto, evidenciar que não constitui esse retorno apenas um resgate de técnicas, mas uma atualização destas em conexão com as novas tecnologias, como as mídias digitais. O novo e o antigo aglutinam suas diferentes atuações e formações e trazem à tona novas linguagens contemporâneas. Uma constatação desse comportamento é a instalação "Fabricated Harvest" (Colheita Fabricada), projetada pelos artistas americanos John Adams e Erika (Ricki) Dwyer:

4 Material elástico reutilizável de peso leve muito utilizado na arquitetura. Cf.

Barrisol Normalu. [Estruturas de tetos esticados]. França: [s.n.], 2014. Disponí-

vel em: <http://en.barrisol.com/index.php>. Acesso em: 09 nov. 2014. 


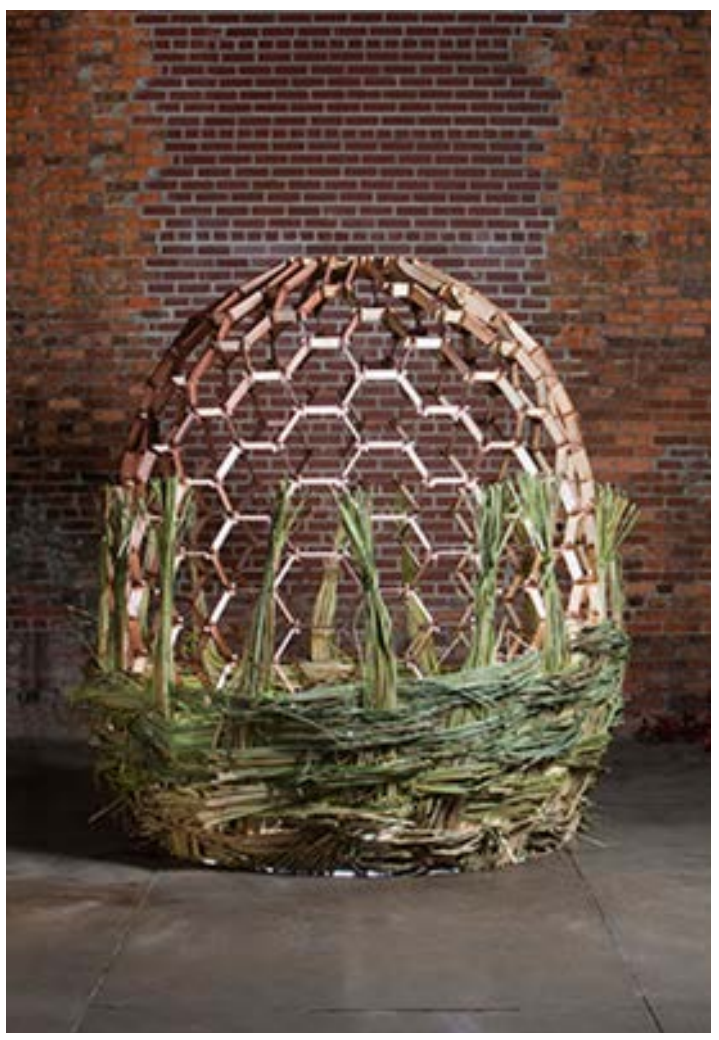

Figuras 14: A instalação "Fabricated Harvest", projetada por John Adams e Erika Dwyer. Fonte: ADAMS, J. DWYER, E. Fabricated Harvest. [S.I.: s.n.], 2009. Disponível em: <http://www.substratumdesign.com/Fabricated-Harvest>. Acesso em: 09 nov. 2014.

Utilizando o mesmo princípio de composição dos kusudamas 5 , Dwyer e Adams combinaram tecnologia digital, tecelagem tradicional e hand-made. Foram feitos 748 hexágonos de madeira cortados a laser e condicionados em um cesto de tecelagem tradicional. A ideia girou em torno da palavra sankofa, originária da língua akan (tribo da Gana), que significa "voltar e buscar". A instalação buscava incorporar o espírito de adquirir e compreender o conhecimento do passado para então poder construir o futuro. Os artistas utilizaram os softwares gráficos "Rhinoceros 3D" (ou Rhino) e "Grasshopper" para criar um roteiro de concepção em cima de uma elipse com padrões hexagonais.

O "Grasshopper" é um editor gráfico em algoritmos, ao passo que o "Rhino 3D" é um software de modelagem digital. Em integração, esses programas possibilitaram construir uma malha geométrica padronizada e aplicá-la em um objeto 3D complexo, como a elipse. O padrão hexagonal tem grande valor estético, como constata Azevedo (1988, p. 10):

Mesmo os animais e insetos, [...], fazem com que seus objetos tenham uma finalidade de uso. $O$ fato de a colmeia ter um desenho hexagonal é para que o mel não escorra, permitindo a cada uma das abelhas armazená-lo.

Nota-se então que há grandes pilares de significação na obra de Adams e Dywer: 
o tradicionalismo se conecta com as linguagens digitais através de conceitos da geometria. Compondo mais um exemplo, especialmente na questão do craft, técnica que necessariamente abarca o âmago do origami, citamos o estúdio "Mode/modeLab", estúdio de design e investigação coletiva com sede na região do Brooklyn, Nova York. Fundado por Ronnie Parsons e Akos Gil, o estúdio se propõe a formar e informar diversas pesquisas aplicadas em conexões com materiais e processos. Mode/modeLab promove diversos workshops, experimentações e estudos sobre módulos, materiais diversos e prototipagem híbrida entre hardwares e softwares. Nos workshops, são utilizadas ferramentas digitais como os programas usados por Adams e Dwyer (Grasshopper e Rhino), além do software "Maya" e os microcontroladores "Arduino". Dentre as propostas experimentais, um dos objetivos é construir protótipos físicos e virtuais que se comuniquem com as pessoas e com o mundo ao redor. Há uma relação íntima dentro do estúdio Mode na utilização transdisciplinar das linguagens digitais (diversos programas de computador para modelagem, programação e mapeamento matemático) com as tecnologias físicas (sensores remotos e máquinas industriais de corte a laser - $\mathrm{CNC}$ ), bem como as linguagens tidas mais tradicionais e milenares (kirigami6 e o craft em si).

Ao aglutinar inúmeros processos diversificados como os citados, o resultado é uma grande esfera sígnica que contém em sua essência a estética relacional 7, a pulsação das antigas e das novas linguagens híbridas. Um dos trabalhos mais relevantes do estúdio Mode/modeLab é a exposição "The business of Aura" (O Negócio da Alma), em Nova York, em que há uma forte presença do kirigami.

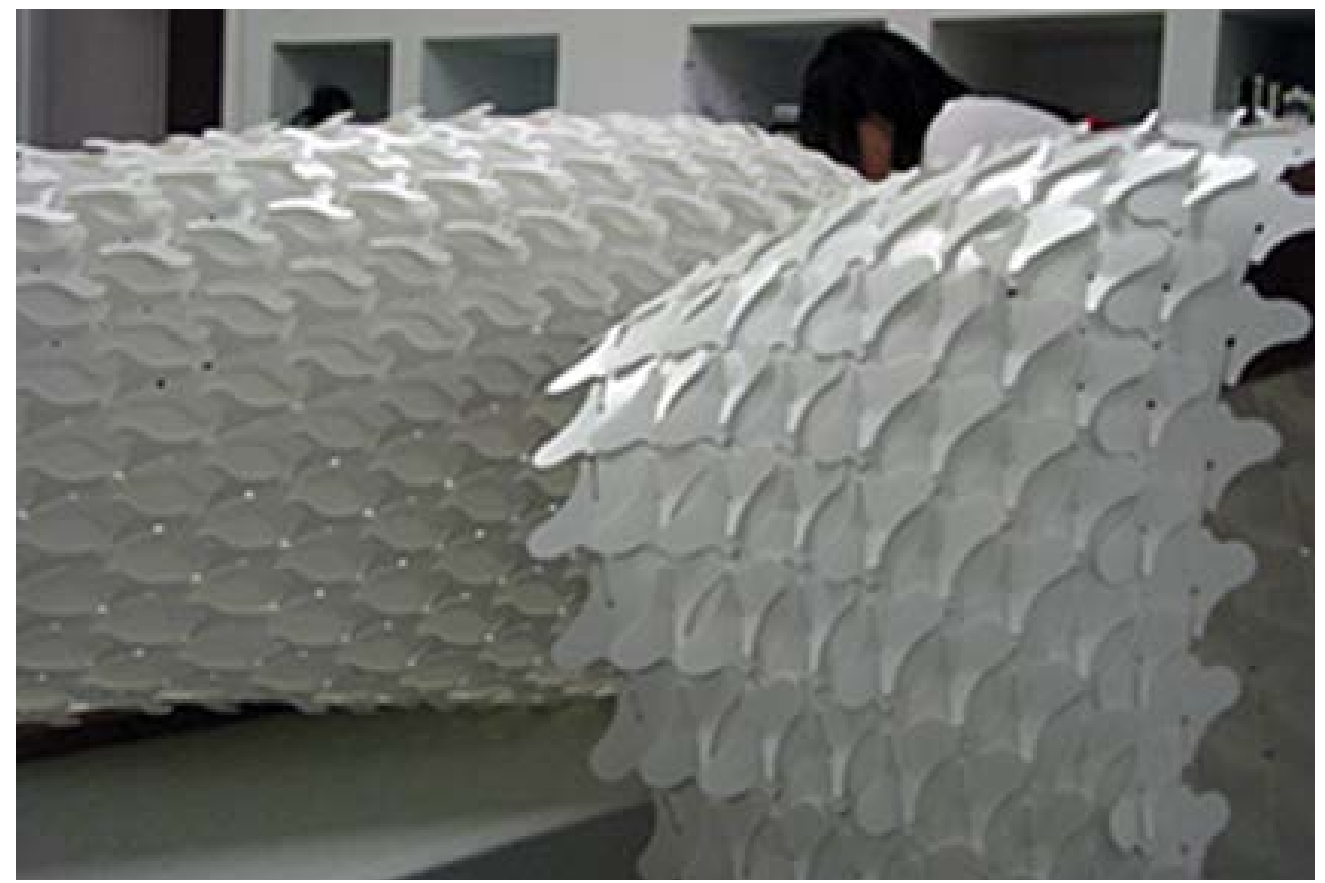

Figura 15: Alguns protótipos da instalação "The Business of Aura", por Mode/modeLab. Fonte: AKOS, G. PARSONS, R. Mode Lab: education by design. [S.I.: s.n.], 2013. Disponível em: <http://lab.modecollective.nu/>. Acesso em: 09 nov. 2014. 
A exposição inclui pintura, desenho, fotografia, protótipos esculturais e instalação. Nela, buscou-se trazer à tona o potencial do processo de produzir a aura, ou alma, e focar metodologicamente em elementos como a qualidade de materiais, tato superficial, geometrias marcantes, formas animadas e a luz. Outro trabalho do Mode/Lab, em colaboração com o estúdio "Tietz-Baccon", é o "Material Inteligence", que teve grande contribuição no âmbito do craft e da experimentação de materiais diversos - além também da exploração das formas, texturas, cores e padrões de mosaicos em formas orgânicas. O "Material Inteligence" é uma oficina de prototipagem que acontece todo mês de agosto, em Nova York desde 2010, e que envolve o trabalho tanto de profissionais quanto de estudantes na concepção de uma variada gama de objetos orgânicos.

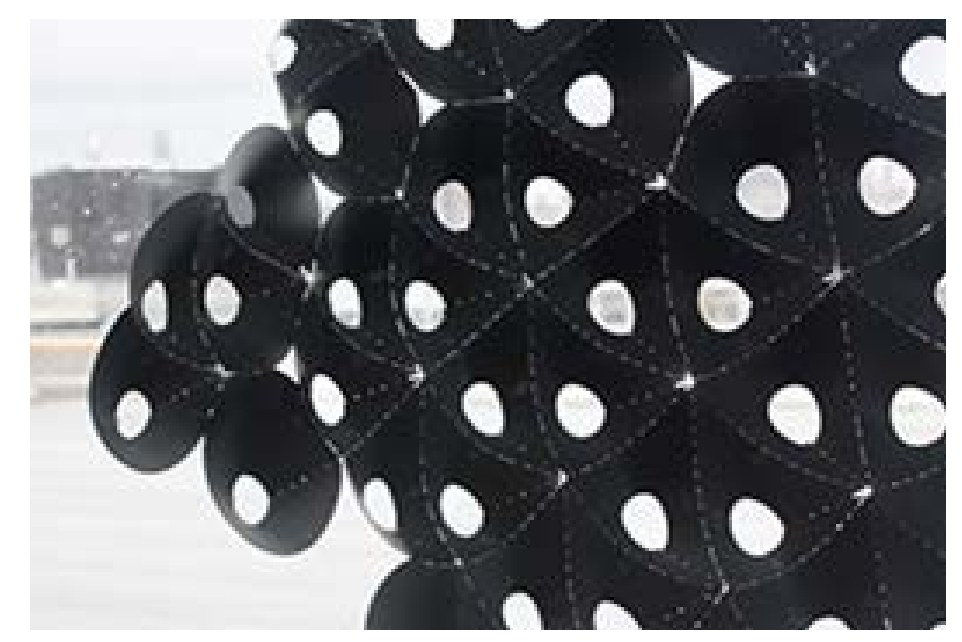

Figura 16: Oficina Material Inteligence, por estúdio Mode/modeLab. Fonte: AKOS, G. PARSONS, R. Mode Lab: education by design. [S.I.: s.n.], 2013. Disponível em: <http:/lab.modecollective.nu/>. Acesso em: 09 nov. 2014.

O "Material Inteligence" possui como briefing 8 a relação entre o objeto projetado e as forças perceptíveis/táteis que giram em torno desse objeto e, através deste processo, navegam entre as multiplicidades de força. Os protótipos servem como links ativadores entre a arte inovadora e materiais de pesquisa, unindo estrategicamente a fabricação digital, tecnologias contemporâneas e ambientes associativos. Para obter o kirigami ilustrado pelo estúdio Mode, já não se precisa mais de tesoura e cola, usam-se máquinas de corte a laser e princípios de união modular intensos e associativos. Entre as forças que resguardam os protótipos do "Material Inteligence", há uma gestão em particular que carrega intenso raciocínio sobre a modulação e a conexão, importante também para o origami modular. O origami dos dias hoje é uma constante exploração de formas e atuações que nem sempre estão condensadas na figura do papel. Isso porque o origami/kusudama/kirigami transcende a limitação do material - ele é, antes de tudo, uma ideia - a principal ferramenta de um artista/designer. 


\section{Conclusão}

Buscamos neste artigo elencar e analisar alguns dos muitos projetos artísticos híbridos que o origami permeia em nossa realidade contemporânea. Vimos que a unilateralidade de conceitos tem se perdido para dar espaço a meta-ações transdisciplinares. Os artistas e/ou designers atingem, com o auxílio do origami e dos crafts, novas formas de explorar materiais, intervenções urbanas, produtos, arquitetura, entre outras áreas da criatividade. Pesquisar o origami mostra-se como um leque extremamente diversificado e benéfico tanto aos profissionais do criativo, quanto à sociedade e às indústrias. Percebemos que hoje as dobraduras passaram a atuar de maneira mais ativa não exclusivamente no papel, mas em outras vias/materiais e reflexões. Tal comportamento do origami o transfigura de fato em uma ferramenta inovadora, garantindo aos projetos versatilidade, estética e sustentabilidade.

\section{Referências Bibliográficas}

ARGAN, G. C. História da arte como história da cidade (trad. Pier Luigi Cabra). 5. ed. São Paulo: Martins Fontes, 2005.

AZEVEDO, W. O que é Design. São Paulo: Brasiliense, Col. Primeiros Passos, 1988. Os Signos do Design. São Paulo: Contato Imediato, 1994.

BONSIEPE, G. Design, Cultura e Sociedade. São Paulo: Blucher, 2011.

BOURRIAUD, N. Estética relacional. São Paulo: Martins Editora, 2009.

DELEUZE, G. GUATTARI, F. Mil Platôs: Capitalismo e Esquizofrenia (trad. Aurélio Guerra Neto e Celia Pinto Costa). Rio de Janeiro: Ed.34, 1995.

DELEUZE, G. A Dobra: Leibniz e o barroco (trad. Luiz B. T. Orlandi). Campinas: Papirus, 1991.

FLUSSER, V. O mundo codificado: por uma filosofia do design e da comunicação (trad. Raquel Abi-Sâmara). São Paulo: Cosac Naify, 2007.

HULL, T. LANG, R. Origami design secrets: mathematical methods for an ancient art. Nova lorque: The Mathematical Intelligencer, 2005.

KAZAZIAN, T. Haverá a idade das coisas leves: design e desenvolvimento sustentável (trad. Eric Roland Rene Heneault). 2. ed. São Paulo: SENAC São Paulo, 2005.

LÉVY, P. O que é o virtual? (trad. Paulo Neves). São Paulo: Ed. 34, 1996.

MORIN, E. Introdução ao pensamento complexo. Porto Alegre: Sulina, 2011.

SERRES, M. Os cinco sentidos: filosofia dos corpos misturados 1 (trad. Eloá Jaco- 
bina). Rio de Janeiro: Bertrand Brasil, 2001.

AKOS, G. PARSONS, R. Mode Lab: education by design. [S.l.: s.n.], 2013. Disponível em: <http://lab.modecollective.nu/>. Acesso em: 09 nov. 2014.

ADAMS, J. DWYER, E. Fabricated Harvest. [S.l.: s.n.], 2009. Disponível em: <http:// www.substratumdesign.com/Fabricated-Harvest>. Acesso em: 09 nov. 2014.

BACCl, A. et al. Veasyble. [S.l.: s.n.], 2009. Disponível em: <http://www.veasyble. com/project.html>. Acesso em: 20 jul. 2014.

BOSSE, C. RIECK, A. WALLISSER, T. Milan Rinascente window. Milão, [s.n.], 2010. Disponível em: <http://www.l-a-v-a.net/projects/milan-rinascente-window/>. Acesso em: 20 jul. 2014.

BOSSE, C. RIECK, A. WALLISSER, T. Digital origami emergency shelter. Austrália, [s.n.], 2011. Disponível em: <http://www.l-a-v-a.net/projects/digital-origami-emergency-shelter/>. Acesso em: 09 nov. 2014.

BOSSE, C. RIECK, A. WALLISSER, T. Digital origami tigers. Austrália, [s.n.], 2010. Disponível em: <http://www.l-a-v-a.net/projects/digital-origami-tigers/>. Acesso em: 09 nov. 2014.

GANJAVIAN, A. KAWAMURA, K. P. Oyster. [S.l.: s.n.], 2009. Disponível em: <http:// www.studio-kg.com/oyster/>. Acesso em: 20 jul. 2014.

GARDINER, M. Oribotics. [S.l.: s.n.], 2004. Disponível em: <http://matthewgardiner.net/art/Oribotics_origin>. Acesso em: 09 nov. 2014.

HERNANDEZ, R. Veasyble by GAIA. [S.I.]: Yatzer, 2010. Disponível em: <http:// www.yatzer.com/Veasyble-by-GAIA>. Acesso em: 20 jul. 2014.

JOBSON, C. New Origami Street Art in Angers, France by Mademoiselle Maurice. [S.l.]: Colossal, 2013. Disponível em:

<http://www.thisiscolossal.com/2013/06/new-origami-street-art-in-angers-france-by-mademoiselle-maurice/>. Acesso em: 20 jul. 2014.

MERCIER, A. PÊCHEUX, V. Faux Plis. [S.l.: s.n.], 2009. Disponível em: <http://www. veroniquepecheux.com/>. Acesso em: 20 jul. 2014. 


\section{Autores}

\section{Samanta Aline Teixeira}

Bacharela em Design Gráfico pela Universidade Estadual Paulista Júlio de Mesquita Filho (UNESP/Bauru) em 2012; foi pesquisadora de Iniciação Científica durante a graduação, financiada pela Fundação de Amparo à Pesquisa do Estado de São Paulo (FAPESP)

Bauru, São Paulo, Brasil

laranjasat@gmail.com

Lattes: http://lattes.cnpq.br/1644868350215025

\section{João Fernando Marar}

Bacharel em Ciência da Computação pela Universidade de São Paulo (USP/São Carlos) em 1985; mestre em Ciência da Computação e Matemática Computacional pela Universidade de São Paulo (USP/São Carlos) em 1992; doutor em Ciência da Computação pela Universidade Federal de Pernambuco (UFPe/Recife) em 1997; pós-doutor pela Universidade de Lisboa, Departamento de Informática em 2007-2008

Bauru, São Paulo, Brasil

fermararafc.unesp.br

Lattes: http://lattes.cnpq.br/1233049484488761

\section{Dorival Campo Rossi}

Doutor em Comunicação e Semiótica (PUC) em 2003; mestre em Comunicação Visual (USP) em 1996; e Arquitetura (USP) em 1990; experiência docente internacional na Universitat de Belles Arts de Barcelona (UB/Espanha)

Bauru, São Paulo, Brasil

bauruhausayahoo.com.br

Lattes: http://lattes.cnpq.br/9128216674908032 